\title{
A Família como Patrimônio: A Construção de Memórias entre Descendentes de Imigrantes Italianos
}

Maria Catarina Este artigo tem por objetivo analisar de que forma a noção de pertencimento tem Chitolina Zanini UFSM sido reivindicada por descendentes de imigrantes italianos em Santa Maria, na região central do estado do Rio Grande do Sul e, em especial, o papel que a família tem desempenhado na busca pelas origens ${ }^{2}$. A construção da italianidade, desde a partida dos emigrados italianos até as gerações atuais, foi um processo complexo no qual seres humanos, natureza e cultura interagiram de forma a possibilitar o enraizamento do migrante em terras brasileiras. Quando saíram da Itália, a partir da década de setenta do final do século XIX, não se sentiam italianos no sentido de um pertencimento nacional, mesmo porque a unificação italiana se dera havia pouco e muitos não concordavam com ela. Eram moradores de um paese e pertencentes a determinada localidade, que se comunicavam por meio de dialetos específicos e adoravam santos distintos. Já na partenza, onde se encontraram genericamente na situação de emigrados italianos, apesar das diferenças culturais, um sentimento de identidade coletiva começava a se expressar. Eram solidários na mesma experiência social: a travessia.

Nas colônias procuravam, sempre que possível, manter a proximidade com seus conterrâneos de localidades e regiões da Itália. No contato com a sociedade nacional eram vistos como italianos genéricos e assim se assumiram nas situações de encontro. A partir do momento em que recebiam os lotes e começavam a desenvolver seus cultivos, construir suas casas e ostentar o fruto de seu trabalho, a representação de colono italiano no Brasil adquiria sentido. Tornavam-se proprietários, alimentavam-se bem, trabalhavam em família e cultivavam sua fé, elementos que permitiram manter viva um pouco da ordem cultural da terra de 
Essas representações ganhavam força pelos exemplos individuais de imigrantes que haviam enriquecido e em comemorações como as efetuadas no Cinqüentenário da Colonização Italiana no estado do Rio Grande do Sul, em 1925 - quando, numa parceria entre o governo local e o italiano, foi elaborado um álbum escrito em língua italiana, no qual se exaltavam à exaustão as virtudes e o empreendedorismo dos colonos italianos. A publicação é uma reverência aos frutos do trabalho dos pioneiros na América brasileira, bem como das virtudes civilizatórias que estes teriam transplantado da Itália para cá. Além disso, por meio das pregações religiosas, toda uma construção do migrante como herói-mártir se processava. No Brasil, construirão, para si mesmos e para a sociedade nacional, a imagem de que eram homens ordeiros, trabalhadores e apegados à família e à fé. Serão essas as qualidades incansavelmente auto-atribuídas, bem como reconhecidas como pertencentes ao imigrantes e às gerações sucessivas às suas. Na maior parte das narrativas com as quais trabalhei, fossem as advindas de descendentes ou de intelectuais locais, as construções se estabeleciam como se houvesse um período anterior à chegada do imigrante na qual a terra era improdutiva e inabitada e um período posterior em que se encontra civilização, riqueza e bem-estar. Antes, o mato e as feras selvagens; depois, as roças, as casas, a natureza domesticada e já integrante do universo simbólico dos imigrantes.

As relações "tranqüilas" entre imigrantes e seus descendentes e a sociedade local dar-se-iam até as primeiras décadas do século XX e os acontecimentos relativos à II Guerra Mundial quando, a partir das posições políticas adotadas pelo governo brasileiro, os italianos e seus descendentes se transformam em inimigos e "perigos" nacionais. O Brasil, integrando o grupo dos países aliados, lutará contra o Eixo, formado pela Itália, Alemanha e Japão. Em verdade, as campanhas nacionalizadoras patrocinadas pelo Estado Novo (1937-1945) começaram antes dos acontecimentos da II Guerra Mundial, contudo, seria nesse período que muitos sentimentos e ressentimentos dirigidos a imigrantes e seus descendentes teriam respaldo para se manifestarem de forma repressiva. Para os imigrantes e descendentes que sofreram perseguição, as humilhações públicas não tinham razão de ser, pois muitos nem sabiam o que se passava na Itália e se sentiam brasileiros de algum modo. Muitas vezes, eram repreendidos por autoridades policiais por se manifestarem em seus dialetos, pois havia sido proibido o uso da língua italiana, e algumas famílias temiam usá-la em casa, pois, segundo eles, “ouvia-se atrás das portas".

Os domínios da casa, que permitiram às gerações sucessivas de imigrantes o processo de enraizamento em terras brasileiras, foram, nesse período, lugares onde não se podia estar privadamente. Pais reprimiam filhos que falassem italiano, irmãos reprimiam irmãos, filhos reprimiam pais e, dessa forma, os domínios da casa se transformaram em espaços tensos. No contexto geral, foram os filhos, que iam à escola, os mensageiros das novidades nacionais. Com receio de repressões, muitas famílias destruíram livros, objetos, fotos, documentos, 
ou seja, elementos que pudessem, de algum modo, revelar pertencimento italiano. Denominei esse processo de varredura cultural, o qual fez com que muitas famílias, que ainda tinham em suas memórias informações acerca do processo migratório e das histórias dos antepassados, preferissem o silêncio e a omissão dessas informações às gerações sucessivas. A história do grupo passou a estar associada às humilhações sofridas durante o período repressivo. Além disso, ser colono representava ser "grosso" e atrasado, e mesmo aqueles descendentes que haviam migrado para o mundo urbano e ascendido socialmente carregavam consigo essas representações.

Contudo, após a década de setenta do século XX, quando dos festejos de um século de colonização italiana no estado do Rio Grande do Sul, muitos descendentes, que haviam conquistado posições sociais e econômicas de destaque, almejavam fazer valer suas origens distintas no cenário da sociedade nacional. Com o incentivo do governo italiano para que se promovessem cursos de língua e cultura italianas, em pouco mais de duas décadas, eram milhares os alunos em todo o Estado. Em Santa Maria, foi criada, no ano de 1985, a Sociedade Giuseppe Verdi, fundada por membros das classes médias e altas que desejavam resgatar a cultura e língua italianas. Essa Sociedade se transformou, em 1990, na Associação Italiana de Santa Maria. Posteriormente, criou-se o grupo de danças Felic'Italia e, em 1994, foi aberta uma Agência Consular local.

\section{A BUSCA DAS ORIGENS}

Quando iniciei a pesquisa de campo, em 1997, tinha como objetivo investigar como se processava a revivificação étnica local nas entidades italianas e em seus membros, que investiam tempo e recursos próprios na visibilização e valorização da cultura italiana. Ao longo do convívio com muitos desses indivíduos e alargando meu universo de pesquisa para outros segmentos socais de descendentes, observei que aspectos diferenciados se tornavam importantes na busca da valorização da cultura italiana. Em verdade, muitos descendentes encontravam imenso prazer nas atividades que exerciam nas entidades e outros estavam, por meio das descobertas proporcionadas pelas entidades e pelos Centro de Pesquisas Genealógicas de Nova Palma e pelo Museu do Imigrante de Vale Veneto, também se autoconhecendo. Eram indivíduos membros das classes médias locais que encontraram, nas pesquisas efetuadas para desvendar suas origens, informações que lhes permitiam agregar a si o itinerário de sucesso dos imigrantes pioneiros, considerados heróis e civilizadores. Dessa forma, no mercado local e regional de bens simbólicos, as origens italianas se transformavam num elemento que se somava positivamente às suas identidades. Para muitos, desvendar de onde provinha sua família, qual o 
itinerário dos pioneiros, o que faziam, por que vieram para a América, eram questões que assumiram uma força simbólica muito grande. Alguns, também, refizeram, às avessas, a trajetória dos imigrantes, do Brasil à Itália, procurando conhecer as regiões, as localidades e especialmente, as casas onde haviam habitado os antepassados. Para determinados descendentes, esse foi um encontro que possibilitou reflexões sobre suas vidas e seus próprios itinerários pessoais.

Muitas famílias haviam começado a busca pelas origens na pretensão de entrar com processos de dupla cidadania, enquanto outros a faziam visando somente cultuar os antepassados, considerados exemplos. Dessa forma, a travessia se transformava, por meio das narrativas, no mito de origem da condição de ítalobrasileiro, ou seja, o evento mediante o qual os descendentes atuais refaziam, partindo de si mesmos, a trajetória dos antepassados. Migrar, colonizar, ascender, eram esses os elementos que se apresentavam nas narrativas quando da construção dos itinerários. Nas representações, os emigrados são seres ordeiros, trabalhadores, religiosos, apegados à família e tais características, pelas construções narrativas, somam-se às suas próprias pessoas. Dessa forma, para muitos, desvendar as origens é também um modo de promover um crescimento da auto-estima, uma vez que socialmente o imigrante italiano é considerado um exemplo de empreendorismo e de sucesso. Sucesso esse que se expande aos descendentes, sendo que as virtudes étnicas (Seyferth 1993:41 e Renk 2000:164) se agregam ao descendente. Além disso, nas trajetórias, o herói civilizador representado pelo antepassado é aquele que vence a natureza hostil e que possui características que são transmitidas por linha de descendência. O pioneiro representa o domínio da passagem de despossuído no país de origem para civilizador e proprietário em terras estrangeiras.

Algumas famílias, com a finalidade de traçar o itinerário genealógico do emigrado até os descendentes atuais, refizeram laços de parentesco e começaram um investimento na montagem de uma história familiar que valorizasse os membros portadores de determinada trajetória de origem. Denominei esse processo de memórias em construção. Por que em construção? Porque, em conseqüência dos acontecimentos relativos à II Guerra e à varredura cultural ocorrida, muitas famílias sabiam serem descendentes de italianos, mas possuíam pouca ou nenhuma informação acerca de seus antepassados e de seus itinerários ${ }^{3}$. Contudo, estavam empenhadas em descobri-las. Começava, dessa forma, na família extensa, uma solidariedade em busca de informações e histórias dos antigos ${ }^{4}$. Famílias começaram a promover festas nas quais reuniam centenas de descendentes, outras realizavam encontros menores e outras reuniam, no máximo, duas gerações a fim de partilharem informações e condensarem esforços na busca das origens.

Observei que o culto à ancestralidade estava presente, senão personificado nos descendentes, mas 
visível enquanto um estilo de vida e de consumo que denotava pertencimento e gosto específico. Dessa forma, pela descoberta das origens, ou seja, de onde provinham seus ancestrais, o quê faziam, o quê comiam, como se vestiam, de que forma rezavam, como casavam, com quem casavam etc., era montada, por um ou vários membros familiares, a história da família que, como processo legitimado pelos descendentes daquele tronco, se tornava a versão oficial da saga familiar. Enfim, essas pesquisas genealógicas assumiam o caráter de um tributo aos antigos.

Em termos antropológicos, considero extremamente importante observar como se construíram essas memórias e como, no mesmo tronco, conforme as ramificações e as posições sociais dos descendentes, as narrativas variavam. Variavam também conforme o tom literário do autor das genealogias. Construir memórias tornara-se um processo que dava prazer aos agentes, pois, aliadas à documentação e às informações históricas, somavam-se anedotas familiares, muita história oral e releituras que os próprios descendentes faziam do tempo dos antigos. Essa construção se transformava num ato que permitia aos indivíduos expandir suas potencialidades narrativas e imaginárias. Além disso, sentiam enorme prazer em valorizar seus genitores e a ascendência mais longínqua. Tratava-se de um tributo aos antepassados que, quanto mais lhes valorizasse, em termos morais, por conseqüência, mais se valorizavam as gerações atuais de descendentes. Ocorria, dessa forma, um processo de reinvenção das tradições (Hobsbawn e Ranger 1997).

A família compreendida enquanto patrimônio advém desse processo de construção das memórias em que se refaz todo um itinerário por meio do qual se procura valorizar determinada "raça" ou "sangue", como designam os descendentes ${ }^{5}$. Como se dá esse processo? A família se torna patrimônio simbólico que agrega valor a seus membros. Portanto, ser membro de determinada família, ter origem italiana e compartilhar de um itinerário de sucesso valoriza positivamente a identidade do descendente. Patrimônio esse que interage num mercado de bens simbólicos no qual a etnicidade, como num campo (Bourdieu 1983:89), representa uma busca por poder e prestígio. Por fim, a valoração finda por residir na pessoa do descendente, considerado como portador legítimo da saga imigrantista e do histórico particularizado por seus antepassados.

Nesse processo, aquele membro familiar que é detentor de determinadas informações, que podem ajudar na construção das memórias, é invocado e passa a ser valorizado, mesmo que sua condição de classe não condiga com a narrativa familiar atualizada, marcada pela trajetória de ascensão social do emigrado para o descendente melhor colocado socialmente. Dependendo do âmbito das construções, ele pode ser o avô, ou em termos mais extensos, pode ser um parente idoso mais distante. Esse personagem, em muitos sentidos, lembra a figura do narrador (Benjamin 1980), ou seja, aquele que troca, que repassa experiências, suas ou de 
outros e que, enquanto as transmite, partilha. Partilha essa que se transforma em processo de conhecimento. É, nas palavras de Halbwachs (1990), um quadro vivo, forte em termos grupais, porque possui a força da experiência. Ele representa o elo vivo do tempo dos antigos para o tempo dos novos. Tempo esse que é uma construção simbólica e existencial de um determinado mundo onde determinadas ordens ainda são vigentes.

Esses guardiões efetuam uma certa domesticação discursiva do que pertence ao mundo da "tradição" e o que poderia ser positivamente a ele agregado. Alguns deles, por mim entrevistados, tinham consigo fotografias, objetos antigos e muitas, muitas histórias para contar. Na sua quase totalidade, eram pessoas já idosas que tomavam para si essa missão e que, de épocas em épocas, eram invocadas para perpetuarem a saga familiar, que, em nível doméstico, partilhava-se cotidianamente nas famílias nucleares. Compreendo que a família, enquanto um sistema estruturado de relações interpessoais (Thompson 1993:13), exerce um papel muito importante na transmissão cultural e na noção de pertencimento. Contudo, a memória não é construída somente ali. Ela sofre a influência de inúmeros agentes externos. O que as famílias têm efetuado é uma partilha que adquire significado e por meio da qual os agentes encontram, na saga imigrantista, uma forma de repassar valores e gostos às gerações mais novas. As sagas se transformam, de certa forma, em guias para a ação, e a busca pelas origens numa viabilidade de auto-encontro, atualizadas em linguagens contemporâneas no nível doméstico.

\section{AFINAL, O QUE É MEMÓRIA FAMILIAR?}

Para se compreender como a noção de pertencimento ao mundo italiano é invocada no presente, trabalhei com narrativas de descendentes e com as memórias que eram construídas com base nestas. Como desejava observar de que forma era invocada a italianidade, entrevistei descendentes de idades diversas, homens e mulheres, urbanos e rurais e membros de classes sociais distintas. Almejava, por meio desse convívio, observar como se processava, no cotidiano, a reivindicação de pertencimento e que peso esta tinha em suas existências. A memória é, em meu entendimento, uma obra (Bachelard 1994:8), ou seja, uma construção que se faz na troca e na partilha e, para tanto, ela necessita de espaços e tempos que permitam a sua vitalização. É o que as entidades e algumas famílias têm permitido. Para construir a identidade de italiano no presente, os descendentes a visualizam como uma trajetória no sentido de que, se hoje são ítalo-brasileiros, isso se deve a uma origem que está assentada no passado. Origem essa que é traçada pela construção dessas memórias. A travessia se 
tornou o marco inicial das construções e há, sobre ela, um infinito número de construções individuais e coletivas. É, desse momento em diante, que as trajetórias familiares adquirem sentido.

$\mathrm{Na}$ atualidade, muitas famílias conseguem descobrir de que cidades italianas partiram seus antepassados. Com as informações adquiridas, tais indivíduos agregam à construção das memórias do italiano genérico local leituras e estudos que fazem sobre as regiões específicas de onde partiram seus antepassados particularmente. Acompanhei casos de famílias que, após descobrirem de quais regiões italianas eram oriundos seus antepassados, começaram a estudar e adotar hábitos culinários, gostos e expectativas de comportamento que seriam considerados típicos dos habitantes daquelas regiões. Era, a partir desse momento, construída uma italianidade regionalizada e particularizada para aquela família especificamente.

Em decorrência da criação das entidades regionalizadas denominadas de Circolos (lombardo, vicentino, emiglia-romana, trentino, veneto), observa-se um processo de reivindicação de identidades particularizadas. Ou seja, muitos se tornam descendentes de italianos genéricos perante a sociedade regional, contudo, entre si, no convívio nas entidades (e fora delas), já se tratam de forma diferenciada, criando, inclusive, rivalidades. Observei famílias, descendentes do mesmo emigrado, que construíam sobre este uma história da travessia particularizada. Para alguns membros, o antepassado poderia ser um homem politizado, um perseguido político, para outros era um camponês pobre, noutras construções era um homem de uma fé inabalável. Enfim, a construção das memórias permite que o emigrado seja interpretado como melhor o descendente atual o quiser e puder fazê-lo ${ }^{6}$.

Isso é legítimo? Considero que sim, pois são essas reconstruções mitologizadas que, nos domínios domésticos, passam a ser a história familiar admitida como válida e que é partilhada e de das quais os descendentes retiram exemplos e força para suas próprias experiências cotidianas. Enfim, retiram-se do passado os elementos observados positivamente e que se prestem de exemplo às gerações presentes. Os aspectos negativos ou vergonhosos são postos de lado e, nas narrativas, ocultam-se como, por exemplo: um antepassado alcoólatra ou com outros vícios, aqueles que tenham cometido faltas que ainda hoje os desabonariam. As prisões e perseguições ocorridas durante o Estado Novo, contudo, sofreram uma releitura e hoje são narradas e transmitidas por entre as gerações como eventos que fortalecem o orgulho étnico.

Além das influências literárias dos religiosos e intelectuais locais na construção de uma italianidade positiva, há a influência da televisão. Quando realizava uma etapa de meu trabalho de campo entre os anos de 1999 e 2000, a Rede Globo de Televisão exibia a novela Terra Nostra, que contava a história da imigração italiana para São Paulo. Nas cenas inicias da novela havia sido exibida a travessia oceânica, o que também influenciou a construção de algumas memórias. O que denomino de memórias em construções se refere ao 
processo, seja individual ou familiar, de refazer-se a si mesmo por meio de um itinerário baseado na origem. O tempo dessas memórias é lacunar e dialético, mais pensado do que vivido7. E, nos preenchimentos das durações (durée), o que importa menos é se os acontecimentos são "verdadeiros". O que lhes atribui realidade é o fato de preencherem espaços significativos. Enfim, compreendo que a reivindicação étnica possui íntima ligação com a valorização num mercado cultural de bens simbólicos. Autodenominar-se italiano agrega valor ao indivíduo. Contudo, como já referido anteriormente, não reside somente nesse aspecto a busca pelas origens. Os indivíduos encontram prazer e sentido nisso e esse é um aspecto fundamental a ser considerado na valorização das identidade étnicas de ítalo-brasileiros locais.

\section{O SAGRADO EXEMPLO DOS ANTIGOS}

A família, como patrimônio, revela outra face da vivência familiar que, em minha compreensão, está relacionada à dinâmica das sociedades modernas, ou seja, ela está se transformando numa forma prazerosa de relação com o mundo. 0 mundo doméstico se tornou, em certo sentido, um mundo do aconchego onde o indivíduo pode devanear e encontrar-se consigo mesmo ${ }^{8}$. Compreendendo que as reivindicações étnicas e toda a reconstrução das memórias que têm sido efetuadas em torno desta revelam que se espera, por meio da partilha das memórias dos antigos e das novas gerações, que a história dos antepassados sirva como exemplo, ou seja, pertencer a um grupo significa adotar determinados valores e condutas, pelo menos idealmente. Por intermédio da constante atualização do mito de origem baseado na travessia transoceânica, das narrativas carregadas de sentimento acerca dos sofrimentos do processo colonizador e das perseguições sofridas durante a II Guerra Mundial, as famílias repassam toda uma forma de compreender e de se relacionar com o mundo à sua volta. A coragem, a abnegação, o espírito empreendedor, o amor familiar, a humildade, o respeito às coisas sagradas, enfim, uma série de elementos que são repassados como constitutivos da forma italiana de ser. A italianidade, desse modo, enquanto sentimento de pertencimento, é acompanhada de expectativas de comportamento e a família se transforma em valor também.

Além disso, para muitos descendentes, a vivência da italianidade se revela como uma forma de relação com o sagrado, em que os elementos referentes às coisas dos antepassados se revestem de mana (Mauss 1974:138), de uma aura mágica que deles se expande. Assim observei objetos serem tratados, tais como: documentos, roupas, rezas, receitas, fotografias, cartas, utensílios domésticos, ferramentas e também anedotas familiares. Por meio do culto às origens, observo que a etnicidade se desenvolve como uma nova forma de 
relação com o sagrado, ou seja, é do passado que os descendentes extraem valores, comportamentos ideais e tipificações que são invocadas no presente. Exemplo esse que espelha uma determinada ordem de mundo e hierarquias vigentes.

\section{POR QUE REIVINDICAR ORIGEM?}

Num cenário transnacional (Ribeiro 2000:173) em que a uniformidade e a diversidade se confrontam com freqüência, reivindicar identidades particulares, em minha compreensão, tem sido uma forma de expressar o pertencimento a uma "comunidade" - nós - que possui uma forma específica de ser, com uma cultura e uma história particular. Além disso, as reivindicações de identidades étnicas se têm revelado um campo no qual o indivíduo pode expressar-se com maior liberdade em termos sentimentais. Na construção dessas identidades, em que a família e seus itinerários desempenham um papel importante, os indivíduos podem, além de construir as memórias, encontrar sentido para suas existências particulares e dar vazão a uma série de sentimentos que se expressam pela trajetória imigrantista. Sentimentos tais como: coragem para vencer adversidades num mundo cada vez mais competitivo; disciplina para suplantar obstáculos; fé para prosseguir cotidianamente; crença de que a família é, sem dúvida, a melhor forma de convívio, entre tantas outras. Compreendo, dessa forma, que a revivificação da identidade étnica italiana em Santa Maria e seu grande sucesso entre as camadas médias e altas se devem ao fato de que, através dos cursos de língua e cultura italiana, das narrativas dos descendentes e de toda uma produção literária local e regional, ser ítalo-brasileiro significa ser portador de uma história de sucesso e membro de um grupo que manteve, apesar de todas as dificuldades, uma determinada ordem moral. Significa, em suma, ser uma pessoa boa, ordeira e, acima de tudo, trabalhadora.

Deve ser considerado também que a Itália hoje é uma potência econômica no cenário global, o que empresta maior valor ainda às origens. Contudo, a Itália moderna e real não é a Itália cultivada nos discursos invocadores das origens. A Itália que possui força é a Itália que foi imaginariamente cultivada aqui. Dessa forma, na reconstrução da identidade étnica e suas particularidades, a família desempenha um papel fundamental como aquela rede de relações sociais baseada no sangue e no parentesco (mas não só) por meio da qual a imigração como um processo maior se particulariza e adquire formas, cheiros, cores e a experiência de personagens vivos. É pelas reconstruções da trajetória do emigrado doméstico, da família, que trajetórias são traçadas e se estabelecem redes de troca de informações e de partilha das dificuldades e dos êxitos.

Por meio da montagem dos processos de dupla cidadania ou no simples prazer que encontram em 
desvendar as origens, muitos descendentes expandem a noção de família do universo nuclear para a família extensa. Relações de parentesco esfriadas pelo tempo e pela ramificação familiar são reaquecidas e elaborase, sobre a noção de sangue e do sobrenome, uma marca que é atualizada constantemente pelo mito de origem da travessia e seus desdobramentos em terras estrangeiras. O sobrenome agrega valor ao indivíduo. E quanto maior a trajetória de sucesso do emigrado e sua de descendência, maior valor possui a família e suas ramificações. Um hábito que não era comum entre descendentes de italianos e que nas últimas gerações tem sido verificado é o de incluir o sobrenome da mãe na prole. E, quando o sobrenome materno, no mercado de bens simbólicos locais, é mais valorizado que o paterno, ele é usado com maior ênfase. Dessa forma, as noções locais de poder e prestígio findam por influir na montagem das histórias familiares, enfatizando ora um emigrado ora outro.

Contudo, para além das análises de cunho mais coletivo, observo que o investimento que muitos indivíduos e famílias têm feito na reconstrução de suas trajetórias familiares necessita de um olhar mais atento, que penetre nos domínios domésticos em que estas adquirem sentido. Pelo trabalho de campo, observei que conjunta à reconstrução de uma trajetória positiva e de sucesso, tais indivíduos criam formas de expressão e de auto-encontro. Da mesma forma, concordo com Sennet (1998), quando este observa que as reivindicações étnicas devem ser interpretadas como forma de auto-encontro em que os indivíduos encontram elementos que se tornam espelhos de si mesmos. Reivindicar etnicidade e mesmo expressá-la tem sentido na medida em que os indivíduos encontrem a si mesmos nessa empreitada. O que equivale a dizer que, enquanto for um espelho positivo e demarcador de um determinado estilo de vida valorizado socialmente, tal reivindicação adquire sentido para o indivíduo e eleva sua auto-estima, ou seja, não se é mais um cidadão genérico, mas, sim, particularizado, estilizado (Featherstone 1995:119).

Além disso, os agentes do movimento étnico podem ser interpretados como "intermediários intelectuais" (Featherstone ibidem:71), ou seja, pessoas preocupadas com a identidade, a apresentação, a aparência, o estilo de vida e a busca incessante de novas experiências. Esse processo se observa especialmente nos descendentes das classes médias e altas que possuem uma discursividade mais elaborada acerca de suas origens. Além disso, possuem poder aquisitivo para melhor visualizar determinado estilo de vida por meio de formas de consumo de bens culturais que denotam pertencimento, investir em viagens e pesquisas que garantam detalhes às suas sagas familiares. Possuem também um discurso centrado na valorização da memória como uma escolha na qual a valorização da cultura italiana de origem promoveria uma espécie de estetização da vida cotidiana. Qual a validade de se possuir um estilo de vida visibilizado? Para Featherstone, no âmbito da 
estilizada (ibidem:119). Em suma, estabelece diferenças. Além disso, como ressalta o autor, o triunfo de uma cultura da representação resulta num mundo simulacional, no qual a proliferação dos signos e imagens aboliu a distinção entre o real e o imaginário (ibidem:122).

Essa é, em suma, a dinâmica da ítalo-brasilianidade, ou seja, ela faz sentido aqui, em terras brasileiras como demarcadora de pertencimento e estilo de vida. Fora daqui, na Itália, são brasileiros preferencialmente. Concordo com Seyferth (2000:96) quando aponta que as identidades hifenizadas são uma elaboração de empreendedores étnicos, o que noto, contudo, no tocante aos descendentes por mim pesquisados, é a relevância de se observar como os descendentes incorporam essa hifenização e, mesmo quando ela não é expressa em termos discursivos, de que forma a noção de pertencimento está lá, senão manifesta, latente. Mas, por que a etnia entra como demarcadora do grupo? Por que esses indivíduos selecionam, no interior de uma gama de referências, a étnica? Compreendo que, pelo processo criativo de reapropriação do passado que as memórias permitem, os indivíduos encontram prazer nessas atividades e, além disso, tais recriações promovem auto-encontros e encantamento do mundo, bem como reaquecem relações sociais de parentesco já fragilizadas. $O$ indivíduo recriando a família, recria a si mesmo e, ao mesmo tempo, permite que ela se mantenha viva de uma forma positiva.

\section{CONSIDERAÇÕES FINAIS}

Quando iniciei a pesquisa de campo, em 1997, a atuação dos Circolos era tímida. Contudo, ao longo dos anos, dos intercâmbios e convênios que têm se estabelecido entre Brasil e Itália, essas entidades têm promovido uma rede transnacional de troca e o que denomino de um alargamento da noção do familiar. Como há Circolos em vários países para aonde rumaram emigrados italianos, está se estabelecendo uma rede de italiani nel mondo, de veneti nel mondo, de friulani nel mondo, de vicentini nel mondo etc., ou seja, indivíduos que, mesmo sabendo-se membros de diferentes estados nacionais, compartilham de algo em comum: a origem. $E$, mais do que a origem, o que compartilham é a experiência da emigração transmitida (ou não) por entre as gerações. Enfim, partilham, mais do que elementos culturais similares, de uma experiência: a travessia e seus desdobramentos. A noção de familiar também, pois por meio de viagens, muitos desses descendentes atravessam continentes e países, conhecem-se, hospedam-se em casas de iguais nas origens, ou, ao menos, tornam-se anfitriões destes. Essas entidades, situadas em vários países, promovem essa rede de experiências pela qual compartilham o sentimento de pertencimento a uma Itália imaginada (Anderson 1983) e suas regiões. 
Para Aries, o sentimento de família, o sentimento de classe e talvez, ainda, o sentimento de raça tenham surgido como manifestações da intolerância diante da diversidade, de uma mesma preocupação de uniformidade (1981:279). Aspectos esses que nos levam a refletir também sobre os processos de construções identitárias de cunho étnico e observar nesses múltiplos desdobramentos a viabilidades de análises tais como: até que ponto se tratam de resistência a uma uniformização maior imposta por um modelo global que sufocaria as diversidades? Até que ponto são formas de manifestação individuais de um pertencimento distinto no contexto das sociedades locais, regionais e nacionais dos países hospedeiros? Até que ponto são dinâmicas de grupos considerados minoritários? Até que ponto os indivíduos vislumbram nas origens e no culto aos antepassados uma forma romantizada do passado que permite reencantar o mundo? Até que ponto, numa sociedade na qual os valores se transformam com muita rapidez, os descendentes de italianos, como no caso estudado, não vislumbram na família enquanto instituição e na saga imigrantista elementos que permitem a manutenção de uma determinada ordem moral? Se a imigração italiana ocorrida em finais do século XIX pode ser interpretada como a tentativa de sobrevivência cultural e moral (Alvim 1986 e Grosselli 1987), até que ponto o culto à italianidade hoje não representaria um elemento importante na manutenção também de uma determinada ordem moral que se vê enfraquecida? Dessa forma, as reivindicações étnicas tanto fazem sentido do grupo para fora, na criação e manutenção das fronteiras, como internamente, numa tentativa de constante auto-afirmação e "controle" na reprodução de determinados hábitos, costumes e formas de ser. O que considero relevante, enquanto antropóloga, é observar como se atualizam as dinâmicas das relações sociais e da construção das identidades, processo esse que é social e individual ao mesmo tempo e a família, nesse aspecto, possui um papel decisivo. 


\section{NOTAS}

1 Uma versão preliminar deste artigo foi originalmente apresentada no GT Migrações Internacionais, no XXVI Encontro Anual da ANPOCS, realizado no ano de 2002, em Caxambu, MG.

2 A pesquisa foi desenvolvida, em nível de doutorado, junto ao Programa de Pós-Graduação em Antropologia Social da USP, sob a orientação do professor João Baptista Borges Pereira.

3 Importante ressaltar que não somente o processo repressivo do Estado Novo provocou essa perda. Inúmeros foram os elementos que se somaram àqueles acontecimentos, anteriores alguns, e que findaram por fazer, ao longo de mais de um século de convívio na sociedade brasileira, os imigrantes e seus descendentes a deixarem de cultivar hábitos e costumes "italianos".

4 O tempo dos antigos não é um tempo cronologicamente datado, é antes uma construção simbólica sobre o passado. Para alguns descendentes, o tempo dos antigos era o tempo dos pioneiros, para outros era o tempo dos pais e avós e para aqueles descendentes que haviam efetuado a trajetória do campo para a cidade, o tempo dos antigos poderia ser encontrado no mundo de seus pais, presos a uma ordem de mundo camponesa ainda. O tempo dos antigos, portanto, é uma construção simbólica que quer expressar uma mudança de ordem de mundo, de rupturas entre a tradição e a contemporaneidade.

5 A idéia de tronco que está sendo utilizada neste texto é referência minha. Entre os descendentes se utiliza o termo árvore (genealógica) eventualmente. O mais comum é referirem-se à história da família. Na montagem das linhas de descendência do emigrado às gerações atuais, encontrei gráficos de vários tipos, sendo que algumas montagens são mais descritivas do que gráficas.

6 As construções variavam também, de acordo com o gênero, o grau de instrução e uma gama imensa de variáveis.

7 Diz Bachelard que, "o fio do tempo é cheio de nós... O real não pára de tremer em torno de nossos pontos de referência abstratos" (1994:66).

8 Essa observação já foi feita por Aries, para quem, na modernidade, a família passa a existir enquanto valor e como uma sociedade fechada onde seus membros gostam de permanecer e que é evocada com prazer (1981:273). Além disso, segundo o autor, a família deixou de ser apenas uma instituição de direito privado para a transmissão dos bens e do nome "e assumiu uma função moral e espiritual, passando a formar os corpos e as almas" (ibidem:277). 


\section{REFERÊNCIAS BIBLIOGRÁFICAS}

ÁLBUM Comemorativo do Cinquantenario della Colonizzazione Italiana nel Rio Grande del Sud (1875-1925). 1925. Opera pubblicata in occasione delle feste commemorative. Roma.

ALVIM, Zuleika. 1986. Brava Gente! Os Italianos em São Paulo (1870-1920). São Paulo: Brasiliense.

ANDERSON, Benedict. 1983. Imagined Communities. London: Verso.

ARIES, Philippe. 1981. História Social da Criança e da Família. Rio de Janeiro: LTC Livros Técnicos e Científicos Editora S/A. BACHELARD, Gaston. 1994. A Dialética da Duração. São Paulo: Ática.

_. 1996. A Poética do Espaço. São Paulo: Martins Fontes.

BENJAMIN, Walter. 1980. “O Narrador. Observações sobre a Vida de Nikolai Leskow”. In: Walter Benjamim. Coleção Os Pensadores. São Paulo: Victor Civita/Abril Cultural.

BOURDIEU, Pierre. 1983. Questões de Sociologia. Rio de Janeiro: Marco Zero.

FEATHERSTONE, Mike. 1995. Cultura deConsumo e Pós-Modernismo. São Paulo: Studio Nobel.

HALBWACHS, Maurice. 1990. A Memória Coletiva. São Paulo: Vértice, Editora dos Tribunais.

HOBSBAWN, Eric e RANGER, Terence (orgs). 1997. A Invenção das Tradições. 2 ed. Rio de Janeiro: Paz e Terra.

GROSSELLI, Renzo Maria. 1987. Vencer ou Morrer. Camponeses Trentinos (Vênetos e Lombardos) nas Florestas Brasileiras. Florianópolis: Editora da UFSC.

MAUSS, Marcel. 1974. Sociologia e Antropologia. Vol 1. São Paulo: EPU/Edusp.

RENK, Arlene. 2000. Sociodicéia às Avessas. Chapecó: Editora Grifos.

RIBEIRO, Gustavo Lins. 2000. Cultura e Política no Mundo Contemporâneo. Brasília: Edunb.

SEYFERTH, Giralda. 1993. Identidade Camponesa e Identidade Étnica (Um estudo de caso). Anuário Antropológico 91. Rio de Janeiro: Tempo Brasileiro. p.31-63

. 2000. Identidade Nacional, Diferenças Regionais, Integração Étnica e a Questão Imigratória no Brasil. In G. C. L. Zarur,

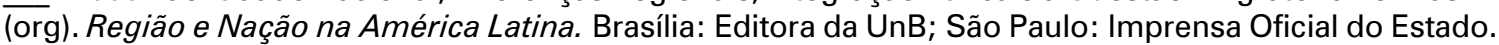




\section{A Família como Patrimônio: A Construção de Memórias entre Descendentes de Imigrantes Italianos} RES U M O

A colonização italiana na região central do Rio Grande do Sul teve início em finais do século XIX e de lá para cá toda uma trajetória de construção de italianidade se processou. A revalorização da noção de pertencimento étnico tem proporcionado uma nova gama de formas de sociabilidade, de troca e de inserção dos indivíduos na sociedade local, mas não só. A família, nessa reconstrução das origens, é o elo que permite ao indivíduo refazer a história coletiva de seu grupo, mas também refazer a si mesmo. O processo de construção das memórias tem, dessa forma, desempenhado um papel fundamental nessa busca e foi por meio delas que minha pesquisa se orientou.

PALAVRAS-CHAVE: família, identidade étnica italiana, memórias.

\section{Family as patrimony: the building of memories among descendents of Italian immigrants}

\section{ABSTRACT}

The Italian settlement in the central region of Rio Grande do Sul state has began in 1877 and from then on a long trajectory of a construction of "italianity" has been processed. The revalorization of the notion of ethnic pertinence has allowed, among other things, new forms of sociability, exchanges and of insertion of individuals in the local society. In this reconstruction of origins, the family is the link that enables individuals to remake the collective history of their group, but also to meet themselves in this process. The construction of the descendents' memories has developed a fundamental role in the search for origins searching and it was through these memories that this research was conducted.

KEY WORDS: family, Italian ethnic identity, memories 